\title{
Chapter 13 \\ The Contribution of Nature-Based Solutions to Socially Inclusive Urban Development- Some Reflections from a Social-environmental Perspective
}

\author{
Annegret Haase
}

\begin{abstract}
Nature-based solutions have emerged to be a major approach or concept when discussing about the sustainable future four cities and are expected to represent solutions for societal problems. When looking closer at this approach, it becomes, however, obvious that the concept is loaded with too many expectations concerning the societal - and, what is more, the social - context of today's urban reality. Furthermore, nature-based solutions are not inherently socially just; when aiming at bringing together environmental sustainability and social equity/inclusion, then a range of issues have to be critically looked at. Set against this background, the paper reflects on the contribution of nature-based solutions to a socially inclusive urban development. In the focus are trade-offs and blind spots of the hitherto discussion. The paper is thought to be first and foremost a positioning paper and is based on five theses. The paper argues, among others, that nature-based solutions offer, if discussed comprehensively and seriously, a potential for creating and shaping more sustainable cities. In order to meet this objective, they should, however, be seen as more than just tools, technologies and instruments. Nature-based solutions have to be improved as a comprehensive approach, especially with respect to their societal and social embeddings and the full picture of their impacts.
\end{abstract}

Keywords Nature-based solutions • Social inclusiveness • Urban development • Social-environmental perspective

\footnotetext{
A. Haase $(\triangle)$

Department of Urban and Environmental Sociology, Helmholtz-Centre for Environmental Research - UFZ, Leipzig, Germany

e-mail: annegret.haase@ufz.de
} 


\subsection{Introduction}

In recent years, two strands of discussion have received growing attention within both social and environmental sciences. First, literature has become more focused on highlighting issues related to urbanization and urban environments; the acknowledgement that the future of our planet will be urban has also resulted in an increased interest in cities within ecology- and "green" sustainability-based studies. Second, urban policy-makers, planners and architects have "discovered" that nature and the environment can be used as a strategy or factor within urban renewal, urban rehabilitation, and smart/sustainable development agendas.

Against this backdrop, the European Commission has increasingly promoted nature-based solutions (NBS) (EC 2015) as a concept or term to describe measures or instruments that can support the maintenance, improvement and restoration of urban nature, green infrastructure and biodiversity. NBS are promoted as an approach to tackle challenges such as climate change and resource (water, energy and food) scarcity The European Commission particularly focuses on the applicability of NBS to cities - 'Urban areas and enhancing sustainable urbanization' are listed as one out of four key opportunity areas for NBS in the EC document. Compared to other terms/concepts such as green infrastructure and (urban) ecosystem services, the NBS concept has a stronger focus on linking ecological/green and economic benefits and is seen to provide a holistic approach to tackling an array of challenges as a result. NBS is not just a scientific concept but also an approach that is attractive for stakeholders, policy-makers and the business environment.

In addition, NBS are also expected to produce a range of co-benefits that contribute to quality of life in cities and are, according to the final report of the EC (2015) expected to help solve various societal challenges in cities. What is striking however, when looking at proposed NBS in the EU document, is that the listed examples either make no direct reference to societal issues or adopt a fairly undifferentiated view of urban societies and the social and power structures within cities. There is no reflection on the potential impacts of NBS on urban life, different population groups, and areas in cities. The possibility that NBS may not always be equally beneficial for all population groups (Kabisch et al. 2016) is not considered. Furthermore, it remains unclear whether NBS automatically lead to socially just and inclusive developments as well or whether they lead to tradeoffs.

Set against this background, the following section will reflect on these issues, and will particular focus on exploring the following questions:

- Which issues need to be considered when looking at the relationship between NBS and the social environment in cities?

- Which tradeoffs exist and what are their consequences?

- To what extent can NBS contribute to socially inclusive urban development?

The paper will present five theses related to the contribution of NBS to socially inclusive urban development and will build on examples from the author's research on social-environmental processes in cities during the last one and a half decades. 
The focus will be on the European context but will also be relevant to the general/ global scale. Prior to outlining these theses, the section below will set the context by exploring the social-environmental nexus in cities from a theoretical angle, and by outlining the foundations, ingredients and ambitions of the NBS approach.

Nature-based solutions in the following, are understood as solutions using green and/or blue infrastructure or dealing with natural resources in a responsible way in order to improve both urban quality of life in and sustainability of cities, or, how the EC put it in its report (2015, p. 5):

Nature-based solutions are understood as living solutions inspired by, continuously supported by and using nature, which are designed to address various societal challenges in a resource efficient and adaptable manner and to provide simultaneously economic, social and environmental benefits.

Socially inclusive urban development is defined as a development considering the needs and wants of all groups of urban inhabitants as well as the different capabilities, capacities and constraints of people to benefit from goods and not to suffer from burdens.

\subsection{Setting the Context: The Concept of NBS and the "Socio-environmental Nexus" in Cities}

\subsubsection{The Concept of NBS}

NBS have been discussed as a term or concept for some years now, mainly within the fields of agriculture (management), industrial design and resilience to the impacts of climate change (Potschin et al. 2015). IUCN defines NBS for the field of nature protection in the era of climate change as

interventions which use nature and the natural functions of healthy ecosystems to tackle some of the most pressing challenges of our time. These types of solutions help to protect the environment but also provide numerous economic and social benefits. (Cohen-Shacham et al. 2016, p. 2)

Recently, NBS have also emerged as a priority area for the EU's Horizon 2020 Research Program. The arguments why such a new approach is needed now relate to a generally growing awareness of the value of nature, the seizing of a momentum where cities have to transform and adapt to manifold challenges. With an explicit relation to economyand technology-based solutions, the NBS approach also seeks to make NBS relevant to business and private sector actors too (pp. 5-6). According to the EC,

NBS in cities should support the emergence of new business models decoupling growth from uneven distribution of resources and an increased reliance on local resources (p.8).

Nature in cities should be employed for a multiple and innovative reuse of degraded urban areas (ibid.). 
Moreover, NBS have the potential to contribute to human health and well-being as well as social cohesion. Consequently, recommended focus areas for action are urban regeneration and the improvement of well-being (pp. 16-17).

Generally, NBS can be seen as a positive way to employ nature more explicitly for a sustainable planning of urban areas including the involvement of the political and economic sphere. And without doubt, there are great opportunities for using green infrastructure or instruments for cost-effective, innovative and healthy solutions that, at the same time, contribute to quality of life and a successful economic performance of a city.

However, two issues must be considered critically here: First, it seems that the NBS approach as defined by the EC and also by IUCN seeks to adapt older concepts such as urban green infrastructure (UGI) or urban ecosystem services (UES) still closer to the economy-related and business-oriented sector. It employs a very business-friendly and de-politicised understanding of urban nature and sustainability and should especially invite developers and investors to take part in their creation, realization and implementation. I am fully in line with Potschin et al. (2015, p. 2) here who demand that:

Yet, a clear link between NBS and these concepts is needed to ensure consistency and avoid redundancy or confusion.

When looking at the scientific debate, NBS are close to what While et al. (2004) in a study on UK cities coined as a "sustainability fix" to describe ways that entrepreneurial urban regimes have sought to (selectively) incorporate the green agenda and changes in rules and incentives structuring urban governance as part of an evolving geopolitics of nature and the environment in order to "greening of the urban growth machine". NBS as described in the EC report seem to fit well as a measure- or instrument-oriented concept fulfilling the idea of sustainability fix.

Second, the EC report in particular does not reflect on the fact that NBS are applied or will be implemented in cities with existing socio-economic and sociospatial differences and inequalities; also IUCN's definition remains very vague in speaking about "numerous social benefits" that could be brought about by NBS. Subsequently, they are discussed in a de-contextualized way which risks ignoring social and justice-related trade-offs.

\subsubsection{The "Socio-environmental Nexus" Within Urban and Cities-Related Research}

Ongoing discussions on sustainable urbanization have resulted in an increasing body of literature and knowledge both in social and environmental sciences. What is more, the number of cross-disciplinary works has also increased. By and large, however, the interplay of social and environmental processes in urban environments remains under-researched. While green infrastructure, greening strategies and environmental goods play the role of an "add-on" in social and planning related debates 
on urban development, the ecological debate shows a lack of attention towards the spatial unevenness of green supply and access to green as well as social inequalities in cities as a basic factor for assessing the distribution of environmental goods and burdens and the feasibility and implementation of sustainability goals (see e.g. the conclusions of the review paper by Kabisch et al. 2016, especially p. 9).

There are a number of central matters of the so-called "socio-environmental nexus" in cities, i.e. the linkages between social and environmental processes and structures:

- an increasing importance of "the urban" in UES/UGI debates but, at the same time, a lacking attention for the existing inequalities and injustices in cities,

- an increasing employment of nature into the strategic debate on future urban development and

- a poor understanding and insufficient dealing with the trade-offs between environmental/ecological and social developments in cities.

Urban environments have become ever more important within sustainability discussion, not least due to growing urban populations, but also due to an increased appreciation of environmental benefits and services and their contributions to urban quality of life. The ecological debate draws on a range of concepts and perspectives that offer the theoretical background for a more sophisticated discussion, among others the concepts of urban green infrastructure (UGI) and urban ecosystem services (UES, see Pauleit et al. in this book). These concepts are looking at urban nature and its functions and services from a human or society-focused perspective and have grown in popularity within the research community over the past few years (see e.g. Kabisch 2015; Haase et al. 2014; Elmquist et al. 2013; Secretariat of the Convention on Biological Diversity 2012, BiodivERsA project URBES, Green Surge etc.). Kabisch et al. (2016) demand explicit consideration of socioenvironmental justice and social cohesion when implementing NBS. A plethora of terms and concepts dealing with futures of sustainable or green urbanization: eco city, smart city, green city, healthy city etc. (see for an overview Jong et al. 2015) have emerged over the years; some of these concepts offer some potential to explore socio-environmental linkages.

However, what is striking within these debates is the limited attention given to basic realities of cities and urban societies concerning (a) the relationship between ES provision and political and social power structures and embeddings (see a very recent paper by Berbes-Blazquez et al. 2016) and (b) the impacts of market logics and power structures on urban policymaking, also with respect to UGI and green strategies (Checker 2011 speaks even of a post-political approach here). By and large, "urban" refers to a specific but largely undifferentiated and de-politicized context, within which ES or GI knowledge can be "applied". Or, in critical cases, nature serves as a legitimation for economically-founded upgrading:

Environmental amenities of all kinds can act as tools for urban entrepreneurialism and gentrification. (Bryson 2013, p. 581) 
There are some doubts whether concepts within the green and sustainability debate "can adequately cater for social justice" (Jong et al. 2015, p.10) but there is no deeper knowledge on this relationship. Berbes-Blazquez et al. (2016) address the relationship between ES provision and social power relations concluding that although power relations extensively impact on ES provision they are largely disregarded in the ES debate so far (p.134).

From the perspective of urban development and planning, the relationship between green spaces and the built environment, as well as the social sphere, have been a topic for a long time (see e.g. Jane Jacobs 1961 on Philadelphia parks). The history of European urban development and urban restructuring of the last decades (especially after WW II) shows many examples of how green spaces were employed to increase urban quality of life, e.g. through the enlargement and improvement of parks, the creation of new green spaces etc. By and large these measures resulted in benefits for many urban dwellers. However, when it comes to the distribution of high-quality green areas, often the better-off dwellers or areas reaped the most benefits; high-quality green (e.g. costly shaped parks) was more often created in or close to upmarket housing environments. As a result, the development of green spaces in a way contributed to the socio-spatial inequalities within the urban environment. Within last decades, urban nature has been increasingly employed as a strategic factor of urban development in a context of inner-city upgrading and the shaping of new upmarket housing schemes, among them river- and waterfronts, and the revitalization of industrial and railway areas (as examples see here Eckerd 2011; Banzhaf and McCormick 2007).

Literature on UGI, UES and NBS has dealt extensively with the positive effects of these concepts and their potential to contribute to related measures for urban green spaces and biodiversity as well as health and quality of life of urban dwellers (Kabisch 2015; Amoly et al. 2014; Krekel et al. 2016; Breuste et al. 2016). What is, however, less common is a critical analysis of the trade-offs, ambivalences and conflicts between the two spheres. It is either presumed that green developments/strategies etc. are per se beneficial for all inhabitants or social cohesion and well-being, or the social dimension is simply missing in many assessments of the impacts of green developments/UES. A debate on trade-offs, e.g. that there is an uneven distribution of and access to UES and that there are winners and losers of green strategies/projects is however slowly developing from the UES research field. Though, there is some anchor points from the perspective of socially-based urban research, e.g. the evolving debate on eco- or green gentrification. This debate is intrinsically concerned with the relationship between green strategies, general upgrading and displacement (Dooling 2009; Quastel 2009; Banzhaf and McCormick 2007: "clean up and clear out"). The debate focuses on revitalization of urban brownfield sites, creation of new neighbourhoods/new built housing projects and upgrading of neighbourhoods, or, as Curran and Hamilton (2012, p. 1027) state:

... environmental improvements result in the displacement of working-class residents as cleanup and reuse of undesirable land uses make a neighbourhood more attractive and drive up real estate prices. 
The NYC High Line, a linear park built in Manhattan on an elevated section of a disused railroad spur 2006-2011, represents still the most prominent and well-known example for those processes but meanwhile, the debate has internationalized including research in Europe, China and other contexts. This debate, however, is rooted mainly in the social-science or critical urban context and is not addressed in the UGI or UES communities so far. It represents, however, also a kind of "add-on" of the general gentrification debate; I am in line here also with Bryson (2013, p. 578) who concludes that.

... the urban natural environment plays an important and understudied role in shaping gen-

trification processes in contemporary cities.

The issues outlined above demonstrate the complexity of the "socio-environmental" nexus in cities and the many challenges confronting researchers. A general obstacle to overcome seems of the lack of two-sided/multi-disciplinary/inclusive debates; the debate on UES and UGI, for example, largely disregards any literature on gentrification and segregation in cities, while the debate on eco-gentrification is largely grounded in the social science perspective and does not differentiate the role and character of "green" or "eco". Eco-gentrification is an "add-on" and seems to be not well-connected to the main streams of debate. Furthermore, there is also a disregard for the political and economic realities of cities when dealing with socio-environmental issues and a lack of understanding of the variegated contexts of cities and path dependencies. In this regard, the NBS concept could be seen in a negative light, as it propagates generalized and de-politicized arguments. On the other hand, NBS could be seen to offer a new approach for discussing the role of nature in sustainable urban development, and therefore a concept that cannot be ignored.

In summary: When reflecting on the conceptual aims of NBS, there are some doubts whether the socio-environmental realities and premises of real-world cities (across Europe) are adequately addressed and considered. The following section will introduce and expand on five theses that should serve to enhance the discussion and qualify the debate on the potential opportunities and limitations of NBS for sustainable urbanization. The aim of the reflections is not simply to criticize NBS as such but also contribute to discussions about their benefits and their trade-offs. The underlying assumption is that if we aim to maximize the potential of NBS, must also be aware of their limits.

The following section outlines these ideas in more detail and explores ways of improving the discussion on NBS use and application.

\subsection{Nature-Based Solutions to Support Socially Inclusive Development - Five Theses}

\section{Thesis 1}

Nature-based solutions are not inherently socially inclusive or just. Under certain conditions, they might even work as triggers for segregation and displacement or be employed as deliberate strategies for selective upgrading. 
It is a popular assumption that greening or green strategies generally, or per se, support social justice and social cohesion. This assumption is also made by the EC when introducing the approach of NBS. But the reality in cities is much more complicated, and any debate on the impacts of NBS should consider the full range of possible benefits and potential impacts a strategy, measure or development might have.

Cities are characterized by social and spatial differentiation. Goods and burdens are unevenly distributed over the territory of a city, urban dwellers have uneven access to goods and are unevenly exposed to burdens; living conditions of urban dwellers with respect to housing, services, green etc. differ considerably.

While green developments such as new parks, enlargement of green areas etc. by and large bring about benefits for many urban dwellers, it is more often the more well-off citizens who reap the most benefits, since they can afford to live in areas close to parks, water- or riverfronts or far away from traffic axes or industrial areas. In recent years, urban regeneration projects (of urban brownfield sites as mentioned by the EC report) and new housing projects (as part of re-urbanization or redensification strategies) in particular, have employed green and blue qualities and related services as elements of upgrading. There are many examples of this from large cities across the European continent and Northern America; the emerging debate on eco- or green gentrification has addressed the relationship between environmental qualities and upgrading and displacement deliberately and directly. Examples are new housing areas including many waterfront and riverside developments as well as new, unconventional parks, in short, projects that privilege highprofile developments over the general provision of green and blue services for a larger population (Millington 2015; Banzhaf and Walsh 2006).

Another example is urban gardening projects, a type of NBS explicitly mentioned by the EC report on NBS, too (2015). Many urban gardening projects undoubtedly aim to follow sustainable and community-supportive goals. However, as Steinberg (2015, p. 20) concludes in her study on community gardens in NYC, LA and Vancouver,

...under urban neoliberalism, sustainability is all too easily appropriated as a tool for economic, rather than environmental and human, development ....

Community gardens, even when they emerge as spaces for collective and political actualization against neoliberal forces, may, under certain conditions, contribute to the premises for a rising attractiveness of a residential area and thus - in most cases involuntarily - help to initiate or intensify upgrading and displacement in the affected areas (Baier 2011, pp.184-85).

As a consequence, urban areas that are marketed as eco-friendly and green (and/ or blue) become less affordable for lower income groups (see e.g. Kramer 2013; Eckerd 2011). Smart or green growth thus might go hand in hand with social exclusion or even displacement ("clearing up and clearing out"). To be here: The upgrade in itself is not the problem but rather the oftentimes selective character and the uneven distribution of the resulting benefits (high-quality green housing, access to high-quality green space) and burdens (displacement, exclusion from high-end green spaces) or, to put it differently, the lack of moderately priced or social housing 
within those development schemes. NBS cannot resolve the problem of sociospatial inequality in cities; under circumstances, they can have very positive coeffects for poorer dwellers, too (Curran and Hamilton 2012; McKendry and Janos 2015). But much depends on a deliberate consideration of existing inequalities and the potential unequal chances of gaining access to the benefits of green projects or policies. New governance modes and larger-scale participation as demanded by Kabisch et al. (2016) might be a step into the right direction to overcome this challenge, although the political and power aspect that is inherent within inequality issues should deserves more attention.

\section{Thesis 2}

In order to meet the ambition of combined effects of NBS, existing trade-offs between ecological 'solutions' and their social environment, embedding and impacts have to be seriously examined and discussed.

Thesis 1 dealt with the myth of "unconditionally good green solutions". The second thesis sets existing trade-offs into the focus. As Jane Jacobs stated for Philadelphia parks in 1961 (!), green areas may contribute to improvement in good areas and to further degradation in bad areas. Subsequently, NBS should not be looked at in an isolated but in an integrated manner. For a balanced view, existing trade-offs or even conflicts between the impacts of NBS for urban space, life and people also have to be considered. This would be a topic for a whole paper on its own; however, some examples to illustrate this issue are outlined below.

Green developments, in many cases, contribute to an improved quality of life for urban dwellers. There are, however, also cases where such interventions e.g. an improved access to green, may not increase social coherence but instead go hand in hand with rising prices and displacements. Thesis 1 above addressed incidences of displacement in US or European cities through top-end green housing projects. Here, although causal effects are hard to identify, one can see a link between the 'greening' and market-oriented upgrading. Existing literature has discussed possible solutions to avoid such trade-offs: One proposed option is to carefully analyze social and socio-spatial effects of new housing developments or improvements; the scholarly debate discusses several approaches here; some argue for the integration of social indicators in ex-ante measurements or monitoring systems (see Pearsall 2012 who proposes the inclusion of the vulnerability analysis and indicators into existing urban sustainability planning or environmental quality reviews). Other authors plead for "just green enough" policies that seek to maintain industrial character and working class neighbourhood while improving quality of life without upscale prestige developments or

interrogate how urban sustainability can be used to open up a space for diversity and democracy in the neoliberal city. (Curran and Hamilton 2012, p. 1027)

Similar discussions have emerged in relation to the introduction of environmentallyfriendly technologies such as thermal insulation of residential buildings which under some circumstances also may lead to increasing rents and displacement (Großmann et al. 2014). 
The described trade-offs operate at different scales; so, it may happen that a positive effect on one scale (e.g. a new green space that contributes to quality of life for many inhabitants) may also result negative effect at another scale (rising housing costs in the direct environment of the new green space may lead to displacement of lower-income households or to exclusionary displacement). Trade-offs, moreover, might operate in very different ways: they may be deliberate ingredients of policies (see the employment of green for purposes of upgrading) or just appear as unintended side-effects of policies.

In order to not provide solutions including few and excluding many, the NBS discussion should at least include a debate on exiting or potential trade-offs between environmental and social developments. The focus should be on identifying these trade-offs and examining how they can be avoided or minimized or at least mitigated in a way that meets both the ecological and social dimensions of sustainability. In planning contexts, trade-offs should be considered in light of general goals of quality of life and equity.

\section{Thesis 3}

Nature-based solutions, as currently discussed, do not sufficiently address political and social power structures and embeddings.

One of the most critical shortcomings of the concept of NBS as introduced by the EC (2015) is the de-politicized way it is discussed. As a result, the approach runs the risk of shunning politics, de-linking sustainability from politics/power and, as a result, contributing to a post-political or de-politicized view of green developments. Solutions are discussed against the context of a 'peaceful and good will based lab', showing little understanding of the conflict-saturated realities of modern societies (see also Brand 2016: 25).

Policies in cities are characterized by the interplay of different actors in the field of policies, market and civic society. Decision-making is more or less democratic, top-down or bottom-up, inclusion and participation more or less organized and channeled. Strategies and the ability to assert own interests depend on political power, financial resources and ownership. The respective resources are, in most cases, unevenly distributed; different actors and their interests have very different chances to realize their wants and needs.

The main argument is here that the scientific and practical debate should analyze more explicitly the relations between NBS and their social and political contexts. There are some debates that have dealt with the link between environment-based urban development and the political or power sphere which may deserve some attention in the NBS debate.

In the debate on green gentrification, some scholars have examined the postpolitical character of green upgrading, stating that it is

... becoming a mode of post-political governance that shuns politics and de-links sustainability from justice. Thereby, it disables meaningful resistance. (Checker 2011, p. 212)

Helpful for a more critical debate are approaches which, for example, analyze the political ecologies of urban regeneration as proposed by Quastel (2009, p. 694): 
Political ecologies of gentrification involve tracing the powers of government planners, real estate developers, consumers, and social organizations as they act in relation to urban ecologies and discourses of the environment. Tracing the effects of such discourses on gentrification, and how gentrification utilizes such discourses, contributes to showing how environmental discourses and policies involve issues of distribution, power, and inequality.

In order to move the NBS discussion forward, political and power structures require further consideration. A study by Berbes-Blazquez et al. (2016) is one of very few publications which look at the relationship between ES provision and social power relations. It concludes that there is a need to analyze how power relations underpin policymaking and governance that also determine access, use and management of ES (p. 138).

How could NBS be better embedded into political and power systems? How can they be used for a deliberately inclusive policy-making? A first step for all involved actors would be to recognize the political and power context in which any solution will be settled. A second step would be to apply participative and integrative modes of governance and participation to be sure that the varying wants and needs of the population are considered (see also Kabisch et al. 2016). A third step would be to screen proposed solutions (first and foremost those that involve market players and their interests) with respect to justice issues and to make sure that disadvantaged groups will be more likely to benefit from the implemented measures; here, the expertise of both scientists and practitioners, but also by civic society activists and NGOs is required. In this way, a solution would immediately contribute to justice and social coherence. Here, the creation of incentives for market actors to act in a socially sustainable way could be a step forward. In short: NBS or urban greening strategies are not "beyond political and power structures" but form part of those; for a comprehensive understanding of their impacts and functioning, they should be discussed against this background, and hence, be politicized or re-politicized (see also McKendry and Janos 2015, p. 56). If not, NBS run "the danger - unintentionally - for preparing the epistemic-political terrain for a greening of capitalism" (Brand 2016, p. 27) that might safeguard or create liveability in some places and for some people but will miss the general aim to provide solutions for structural problems that are rooted in the logics and mechanisms of the capitalist system and today's global inequalities and injustices created by it.

\section{Thesis 4}

The concept of nature-based solutions so far do not consider socio-spatial differences as well as different levels of in-and exclusion of people in cities, different everyday life routines as well as differing needs and wants of a heterogeneous and diversifying urban society.

The concept of NBS does not specify its addressees, especially when it comes to the "urban population" or "urban dwellers". This is not just problematic with respect to existing socio-spatial inequalities. It is also denies or ignores the existence of a wide range of perceptions, needs and wants concerning green and urban nature among urban dwellers. A great challenge for the debate on NBS is to adequately consider 
today's ever more differentiated and diverse urban societies. How does one cope with different, diverging or even opposing wants and needs? How can different views on urban nature and green developments be integrated? Who defines what benefits, qualities, good and healthy urban life are at all? How does one cope with the uneven integration of people into participative and opinion-building processes?

In the literature on UES, e.g., there are some studies that point to different perceptions, wants and needs of urban dwellers (e.g. Botzat et al. 2016; Gentin 2011) as well as their different opportunities to make use of or benefit from urban nature (Jones et al. 2009). There is a need to link the NBS or "green" debate with (social science based) debates on urban diversity, inequalities, capabilities, and (in)justice. Existing studies on UGI, UES and NBS have so far a bias with regard to the views and perceptions of middle-class inhabitants and the needs and wants of specific (environment-minded) lifestyle groups; this largely by-passes the views of various precarious population groups including the unemployed, poor families, alternative subcultures, migrants, other minorities (see Berbes-Blazques et al. 2016). The ecogentrification debate, again, considers this fact, stating that ecological projects or solutions often designated for a bourgeois aesthetic (Dooling 2009) and that urban gardening and farms picture a niche or "glossy representations of sustainability" (Steinberg 2015). By and large, the views of low-income groups or people not taking part in participatory events tend to be less considered when discussing on green developments, the potentials of UES or NBS as solutions for a sustainable neighbourhood development.

If we really want to understand the potential of NBS for contributing to social cohesion, communication, empowerment, reduction of inequities etc., we must acknowledge the wide range of potentially opposing perceptions, wants and needs. The development of a more differentiated view and, as explored by Low (2013), the consideration of matters of distributional (Is there green space for all and a fair allocation?), procedural (Is there a fair access to green space?) and interactional justice (Does the green space allow for all to interact safely?) when creating and implementing NBS such as parks, playgrounds or other types of open space would be a large progress for the whole debate on NBS and would it make more than just a middle-class discussion. Solutions that directly address the needs of disadvantaged groups would offer an incentive for those people to get involved and would directly contribute to social inclusiveness. Particularly now, in a situation where most larger European cities are seeing new waves of in-migration and immigration including international migrants and (non-European) refugees, the question of how different parts of urban society look at urban nature and how this nature can be employed for different needs and wants, long-term or even temporary, seems to be crucial. It remains to be seen whether the NBS concept has the capacity to develop such a differentiated view.

\section{Thesis 5}

NBS as they are discussed run the risk to get overloaded regarding their capacities to respond to societal questions and to be easily transferable. 
NBS may be a prerequisite for more sustainable urban development including social inclusiveness. But they are not enough in themselves for reaching (automatically) socially inclusive solutions. At the same time, it seems to be challenging to bring together environmental, social and economic priorities in a balanced way. This is reported e.g. by a study by McKendry and Janos (2015, p. 55) on neighbourhoods in Seattle and Chicago that apply urban environmentalism as a key aspect for their postindustrial development strategy and where, so far,

... efforts to promote economic growth, social and environmental equity, and environmen-

tal protection sit together uneasily.

Pretending this, it is crucial to get a clearer picture of (a) the opportunities and impacts that NBS may have in a more complex setting of urban regeneration (Rodriguez-Labajos and Martínez-Alier 2013) and (b) how different priorities such as economic, environmental and social ones might work together in a coadjutant and cross-fertilizing way. To put it differently: The debate on if and how greening strategies should be deliberately employed for urban restructuring and upgrading has to be complemented by a debate on to what extent urban decision-makers are ready to integrate ideas of social justice and inclusiveness into these greening strategies (see also McKendry and Janos 2015, p. 57). Clearly, NBS offer proper potential for promoting sustainability in a wider sense but they should be seen as part of a more complex-based solution, not as 'the solution' itself. NBS will, in most cases, rather selectively contribute to more sustainability and human well-being; they will be relevant for specific groups, activities, uses and contexts. Reflecting on their limitations as well as the potential allows for a much clearer picture of their outcomes/impacts.

Limits exist surely also with respect to transferability. 'Solutions' that work in one place might have very different effects elsewhere. Expensive greening strategies on former brownfield sites, for example, work only in contexts where the resulting costs can be paid by state and/or private actors. Projects related to urban gardening may be successful given the presence of a motivated and active local community, but will fail if there is apathy and disinterest. The majority of existing examples of successful NBS stem largely from rich cities or, at least, not from poor cities or cities in less developed regions of the world; this is not an incident. Poor cities, in many cases, have other priorities and often do not have the money that is needed for the realization or implementation of NBS; private actors, while easily to be convinced at wealthy places, will be more reluctant there. Therefore, it seems to be crucial to look at the context in which solutions should be implemented, first and foremost on political and power structures and ways of decision-making and in-/ exclusion of certain groups of inhabitants and/or actors. The same holds true for path-dependencies: as it is also underlined by Berbes-Blazquez et al. (2016, p.139) as a general matter for ES provision and management, research and practice debate have to more thoroughly recognize historical ties between social power relations and greening strategies as well as their employment into urban planning, housing construction and green space development. 


\subsection{In Lieu of a Conclusion ...}

The reflections presented in the five theses above demonstrated that the relationship between NBS and the social environment in cities is a complex one and must be considered with respect to their various synergies and trade-offs by both the academic debate and policy-makers and practitioners in cities. NBS offer, if discussed comprehensively and seriously, a potential for creating and shaping more sustainable cities, also in terms of social sustainability and inclusiveness. In order to meet this objective however, they should be seen as more than just tools, technologies and instruments to be applied within urban contexts. Although nature or nature-based solutions are not the only solution to societal challenges in cities, they may become part of a more strategic alliance of environmentally and socially healthy premises and aligned measures for shaping urban space, housing and infrastructure/amenities and aligned measures for shaping urban space, housing and infrastructure/amenities and can serve for more than a "narrow and insufficient corridor of ecological modernization" (Brand 2016, p. 26). To realize such a vision, NBS have to be improved as an approach, especially with respect to their social embeddings and the full picture of their impacts. The NBS concept may shift and change, but can be enriched and completed by new perspectives and ingredients. Even from a critical perspective, NBS in their current conception cannot be seen as incompatible or irreconcilable with social inclusiveness. A balanced view which incorporates different debates, lines of argument and includes a consideration of both pros and cons is however vital. Furthermore, a more holistic view, combining economic, social, environmental and technical elements and components of 'solutions', which does not pit the single dimensions against each other but sees them as ingredients of a larger and inseparable unity, is needed. There is much potential for creating a more comprehensive and in-depth crossover between social and environmental/ecological debates and it remains to be seen whether a convergence between strands of thought will take place and how these discussions will evolve.

\section{References}

Amoly E et al (2014) Green and blue spaces and behavioral development in Barcelona schoolchildren: the BREATHE project. Environ Health Perspect 122(12):1351-1358

Baier A (2011) Urbane Landwirtschaft und Stadtteilentwicklung. Die Nachbarschaftsgärten in Leipzig. In: Müller C (ed) Urban Gardening. Über die Rückkehr der Gärten in die Stadt. oekom, München, pp 173-189

Banzhaf HS, McCormick E (2007) Moving beyond cleanup: identifying the Crucibles of Environmental Gentrification. In: Andrew Young School of Policy Studies, research paper series, working paper 07/29. http://aysps.gsu.edu/publications/2007/index.htm (9.6.2016)

Banzhaf HS, Walsh RP (2006) Do people vote with their feet? An empirical test of environmental gentrification. Discussion paper RFF DP 06-10 
Berbes-Blazquez M, Gonzales JA, Pasqual U (2016) Towards an ecosystem services approach that addresses social power relations. Curr Opin Environ Sustain 19:134-143

Botzat A, Fischer LK, Kowarik I (2016) Unexploited opportunities in understanding liveable and biodiverse cities. A review on urban biodiversity perception and valuation. Unpublished manuscript

Brand U (2016) "Trasformation" as the New Critical Orthodoxy. GAIA 25(1):23-27

Breuste J, Pauleit S, Haase D, Sauerwein M (2016) Stadtökosysteme. Springer, Heidelberg

Bryson J (2013) The nature of gentrification. Geogr Compass 7/8(2013):578-587

Checker M (2011) Wiped out by the "Greenwave": environmental gentrification and the paradoxical politics of urban sustainability. City Soc 23(2):210-229

Cohen-Shacham E, Walters G, Janzen C, Maginnis S (eds) (2016) Nature-based solutions to address global societal challenges. IUCN, Gland. xiii $+97 \mathrm{pp}$

Curran W, Hamilton T (2012) Just green enough: contesting environmental gentrification in Greenpoint, Brooklyn. Local Environ 17(9):1027-1042

de Jong M et al (2015) Sustainable - smart - resilient - low carbon - eco - knowledge cities; making sense of a multitude of concepts promoting sustainable urbanization. J Clean Prod. http:// dx.doi.org/10.1016/j.jclepro.2015.02.004

Dooling S (2009) Ecological gentrification: a research agenda exploring justice in the city. IJURR 33(3):621-639

Eckerd A (2011) Cleaning up without clearing out? A spatial assessment of environmental gentrification. Urban Aff Rev 47(1):31-59

Elmquist T et al (2013) Urbanization, biodiversity and ecosystem services: challenges and opportunities. Springer

European Commission (EC) (2015) Towards an EC research and innovation policy agenda of nature-based solutions and re-naturing cities. European Commission (EC), Brussels

Gentin S (2011) Outdoor recreation and ethnicity in Europe - a review. Urban For Urban Green 10:153-161

Großmann K et al (2014) Energetische Sanierung: Sozialräumliche Strukturen von Städten berücksichtigen. GAIA 23(4):309-312

Haase D, Haase A, Rink D (2014) Conceptualizing the nexus between urban shrinkage and ecosystem services. Landsc Urban Plan 132:159-169

Jacobs J (1961) The death and life of great American cities. Penguin Books, New York

Jones A, Brainard J, Batman IJ, Lovett AA (2009) Equity of access to public parks in Birmingham, England. Environ Res J 3:237-256

Kabisch N (2015) Ecosystem service implementation and governance challenges in urban green space planning - the case of Berlin, Germany. Land Use Policy 42:557-567

Kabisch N, Frantzeskaki N, Pauleit S, Naumann S, Davis M, Artmann M, Haase D, Knapp S, Korn H, Stadler J, Zaunberger K, Bonn A (2016) Nature-based solutions to climate change mitigation and adaptation in urban areas: perspectives on indicators, knowledge gaps, barriers, and opportunities for action. Ecol Soc 21(2):39. http://dx.doi.org/10.5751/ES-08373-210239

Kramer A (2013) Divergent affordability: Transit access and housing in North American cities. In: A thesis presented to the University of Waterloo in fulfillment of the thesis requirement for the degree of Doctor of Philosophy in Planning, Waterloo, ON, Canada

Krekel C, Kolbe J, Wüstemann H (2016) The greener, the happier? The effect of urban land use on residential well-being. Environ Econ 121:117-127

Low S (2013) Public space and diversity: distributive, procedural and interactional justice for parks. In: Young G, Stevenson D (eds) The Ashgate research companion to planning and culture. Ashgate Publishing, Surrey, pp 295-310

McKendry C, Janos N (2015) Greening the industrial city: equity, environment, and economic growth in Seattle and Chicago. Int Environ Agreements 15:45-60. doi:10.1007/s10784-014-9267-0

Millington N (2015) From urban scar to 'park in the sky': terrain vague, urban design, and the remaking of New York City's High Line Park. Environ Plan A 47:1-15 
Pearsall H (2012) Moving out or moving in? Resilience to environmental gentrification in New York City. Local Environ 17(9):1013-1026

Potschin M, Kretsch C, Haines-Young R, Furman E, Berry P, Baró F (2015) Nature-based solutions. In: Potschin M, Jax K (eds) OpenNESS ecosystem service reference book. EC FP7 Grant Agreement no. 308428. Available via: www.openness-project.eu/library/reference-book

Quastel N (2009) The political ecologies of gentrification. Urban Geogr 30(7):694-725

Rodriguez-Labajos B, Martínez-Alier J (2013) The economics of ecosystems and biodiversity: recent instances for debate. Conserv Soc 11:326-342

Secretariat of the Convention on Biological Diversity (2012) Cities and biodiversity outlook. Montreal, 64 pp. https://www.cbd.int/doc/health/cbo-action-policy-en.pdf

Steinberg GW (2015) Cultivating resistance? Urban sustainability, neoliberalism, and community gardens. Thesis submitted in partial fulfillment of the requirements for the Degree of Master of Arts, SIMON FRASER UNIVERSITY Spring 2015

While A, Jonas AEG, Gibbs D (2004) The environment and the entrepreneurial city: searching for the urban 'sustainability fix' in Manchester and Leeds. IJURR 28(3):549-569

Open Access This chapter is licensed under the terms of the Creative Commons Attribution 4.0 International License (http://creativecommons.org/licenses/by/4.0/), which permits use, sharing, adaptation, distribution and reproduction in any medium or format, as long as you give appropriate credit to the original author(s) and the source, provide a link to the Creative Commons license and indicate if changes were made.

The images or other third party material in this chapter are included in the chapter's Creative Commons license, unless indicated otherwise in a credit line to the material. If material is not included in the chapter's Creative Commons license and your intended use is not permitted by statutory regulation or exceeds the permitted use, you will need to obtain permission directly from the copyright holder.

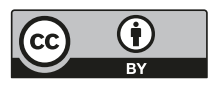

